\title{
Artificial Intelligence and Future Employment
}

\author{
Sapna Khatri ${ }^{1}$, Prof. (Dr.) Devendra Kumar Pandey ${ }^{2}$, Prof. (Dr.) Daniel Penkar ${ }^{3}$ \\ ${ }^{1}$ Research Scholar, Amity University Madhya Pradesh, Gwalior. India ramani.sapna@ gmail.com, \\ ${ }^{2}$ Professor, Amity Business School, Amity University Madhya Pradesh, Gwalior, India dkpandey@gwa.amity.edu \\ ${ }^{3}$ Prof. \& Director- Sinhgad Institute of Management, Savitribai Phule University, Pune, India. drdanielpenkar@ rediffmail.com
}

\begin{abstract}
$\mathrm{AI}$, as one of the technologies of industry 4.0 , is bringing dramatic influence in the existing working setup of organization. AI demands newer work, newer skill-sets, throwing newer challenges, a totally new perspective. This perspective is based on the primary and secondary data collected. There is no single cookie cutter for all challenges. To be future ready, organizations need to prepare themselves through the employment strategies of skill enhancement, new skill development and re-skilling of its human intellect. Whilst AI may threaten to make humans redundant in certain kinds of jobs, it surely opens new vistas for skill-sets, which would be required to manage the new workplaces, and the future employment processes will have to be created around these technologies. The field of AI is growing at break-neck speed, so there are newer things emerging every single day. So this perspective is dated with respect to analysis and outcomes, which have potential to be revisited in short \& medium term. It requires different talent, skills \& techniques for defining solutions and challenging current employment processes. AI Automation, IoT, Cloud computing, Cognitive computing; has been mesmerizing the workplaces. Whilst all the advances in connected world bring about efficiencies and productivity, these create and influence and support employment processes and pose challenges for the organization, fuelling start-ups and entrepreneurship as social and economic development. The field of AI and its influence on HR is an emerging field, with lot of work being done globally. However, how is AI challenging and creating employment opportunities in the organization and helping development of the society is the key areas of study in this paper.This paper elaborates on the usage of AI for future employment opportunities \& challenges.
\end{abstract}

Key words: Artificial Intelligence, Challenges and Opportunities, Employment, Entrepreneurship, Human Resources development.

\section{INTRODUCTION}

Future employment is going to move around the AI technology and connected World. Human Talent of any organization is tacitly driven by culture of the workplace environment. Adaptability is the hallmark of the human race but humans are also driven by inertia to change, they resist change before accepting and adapting it. The sneaking impact of the AI is also provoking these inertial mind-sets. This distrust is further heightened by overabundance of Sci-fi movies, which propagate a super image of the supremacy of the automation and machines over Homosapiens. Hence, it's natural for humans to imagine AI automation as competition, potentially a threat and substitute mechanism. Similar scepticism had greeted all previous industrial revolutions and they had been viewed as anti-human. However, human superiority has remained unshakeable and unscathed thus far. Only common factor has been it takes time to settle in collaboration.

AI will surely throw a unique challenge, a new dimension to the employee functions and social processes in the organizations. The work places are destined to be wedged by the intelligence being built into the working systems, be it the manufacturing shop-floors or support systems, whether it's transactional automation or solutions libraries, whether it's human interface or the assessment interface. Most of these are being influenced by the AI and are exploiting the Big Data, using complex algorithms. All these are transforming today's workspaces to be future ready and influencing employment, which are sharp departure from what has been experienced in any of the prior industrial revolutions. One main differentiator in the previous revolutions was that humans were harnessing the aids of productivity and efficiency developed, for delivery of results. AI is changing this whole equation itself, it puts "intelligence" at the centre of the debate, something which has been exclusive dominion of humans and never been replicated. It may not be true any longer and hence the new set of influential challenges are coming to fore. Few people may be considering this as a threat on their jobs and employment on the other hand few are considering $\mathrm{AI}$ as opportunity and taking leverage of this technology to build or setup their new entrepreneurship venture or enhance their existing setup and adapt the process to this technological revolution.

\subsection{Artificial Intelligence}

AI is an extension of machine learning. In this phase of technological progression, machines are trained to respond not only with specific outcome from the set programs but also to learn, relearn, extrapolate, think and respond on its own. AI is a one of the technological disruptions of industry4.0, where in machine may take over human intellect. [11] AI is remodelling machines as smart as feasible, so that they can learn and solve the problems cognitively, a sole domain and asset of the humans until now. Humans are preparing machines for intelligence purpose without realizing or anticipating its deep 
Sapna Khatri et al., International Journal of Advanced Trends in Computer Science and Engineering, 9(4), July - August 2020, 5272 - 5277

infiltration into their sole domain; this could be a real threat or risk.[2] Though AI is bringing assistance for the employee and changes the dimension of job profile by reducing or eliminating the routine and repetitive job, it enables employer to re-visit the whole gamut of employment and HR processes. AI helps employee to think differently and progressively and allow them to accomplish task in collaboration with machines.

\subsection{Employment}

Employment is to get affianced to any organization to provide or offer services against the remuneration in form of monetary benefits. Organization involves people in form of employee to get the work done from them to achieve organizational goals for the betterment of individual, organization and society at large economically considering the latest use of technology and up gradation of skills. [13] Employment is a progressive process of hiring employees and human talent management. It starts with recruitment and selection and culminates at retirement or separation. [14] It comprises of recruitment, selection, orientation, socialization and finally placement. Training and re-skilling people are also an integral part of employment leading to career and succession planning for the employee under employment. Employment brings mutual benefits for employee and the organization, defined by a frame of contract and defined policies, under which employment can be governed to achieve the common goals and development of both.[12] With the arrival of AI, it is becoming increasingly debatable whether AI will be enabler or competitive force in the employment in the organization. Whereas entrepreneurs are considering $\mathrm{AI}$ as a tool of productivity and enhancing the efficiency of business and employee, a lot of leverage will be dependent on the how the complete business processes are relaid out. Goos et.al philosophise that as the technology effect grows, there is an increase in the relative demand of the highpaid skilled jobs, requiring non-routine cognitive skills. Equally increased demand is seen in low-skilled, low-paid jobs, requiring non-routine manual skills. However, it is seen that there fall in demand of jobs requiring routine manual and cognitive skills, basically the mid-category jobs. The researchers refer to this process as job polarisation.[4]

\subsection{Artificial Intelligence and Employment Processes}

AI is surely and securely entering the industry and in minds of employees with the focus of economic growth.AI is now taking over the tasks, which was earlier managed by humans in the industry, bolstering the claim that machines can be smarter than human employee. Voice assistants, AI bots, Driverless cars, Drones are playing role of employee and imposing employment challenges and becoming the reason of social development. All these execution are leading to dilemma that what kind of employment is needed in the organization for humans now. [5]

\subsection{Problem Statement}

What kind of structure is going to shape the industry? Whether nature of the employment would be horizontal, vertical, managerial or strategic? Weather it will be permanent, temporary, contractual or no employment opportunity for the natural intelligence? Innovation in technology is throwing many questions in the current workspaces. However entrepreneur is accepting this as opportunity and responsibility of dynamic need of developing nation. Few names in entrepreneurship venture with the innovation in technology are as Flipkart, Amazon, Facebook, Alibaba, Ola, and Uber; similarly many online applications are the great examples in the field of entrepreneurship. Start-ups have taken different shapes in their business and venture with the help of latest innovation in technology\& adapting it to their processes, which indicates social development. It creates more employment opportunities in technical field to create or develop in depth logical algorithm. On the other hand it is throwing the challenge on non-technical field. Let's discuss the combination of $\mathrm{AI}$ and human collaboration employment opportunities.

\section{REVIEW OF LITERATURE}

ALLEGIS group published a white paper on AI, which quotes a 2016 report by analyst group IDC, predicting revenues from cognitive systems and AI technologies to jump from $\$ 8$ billion in 2016 to more than $\$ 47$ billion in 2020. The World Economic Forum had forecasted that $60 \%$ of the kids entering school today would end-up working in jobs, which do not even exist today. A study by Oxford Martin School of Economics suggests that $47 \%$ of all American functions will be automated within next 20 years. KPMG has predicted that over 100 Million global knowledge workers will be affected by Robotic process automation by 2025 . However, every prediction is not pessimistic in its outlook. Organization for Economic Cooperation and Development has predicted that $5-10 \%$ of labour would be displaced by intelligent automation but new job creation will offset losses. All these are clear indicators that future employment will have new dimensions, in almost all functions and segments of business. [1]

Georgios Petropoulos, in his research paper, debates about multiple approaches, the effect of AI on the labour market, if it will lead to displacement or productivity effect. He cites a research from Mckinsey Global Institute wherein it is expected that AI will disrupt the society at ten times the speed and three hundred times the scale of previous known industrial revolutions. The impact is expected to be three thousand times higher. [8]

In an article published by BCG researchers, Gallego, Krentz, Taplett, Tsusaka, and Yousif (2019), present the arguments on how AI can help or hinder the growth of employee in the workforce. Whilst they argue that AI algorithms can be biased against women employment, as the current statistical data is adversely tilted in favour of men. The same data resources can be used by AI based HR recruitment tools against the women candidates. However, on the upside, the same AI can be enabler for improving the gender diversity at workplaces. AI based support structure can allow the women to focus easily on their career whilst the AI enables them to manage the daily 
Sapna Khatri et al., International Journal of Advanced Trends in Computer Science and Engineering, 9(4), July - August 2020, 5272 - 5277

chores. Such enablers would help women workforce ratio improve in the future. [3]

In a research findings published by MIT Sloan Management Review, based on the research by Mckinsey Global Institute, it is suggested that by 2030, whilst AI will lead to lesser full-time employment, it will not create massive unemployment as dreaded by many. One of the key reasons identified by this research is that early adopters of AI would tend to focus on innovations for growth, which would lead to higher employment prospects and hence more jobs. The whole gamut of employment and human resource processes will be adapted to leverage AI. [2]

In papers published in International Journal of Advanced Trends in Computer Science and Engineering, Nishad Nawaz (2019) talks about the transformation in the recruitment process of CMMI level organizations, where in Artificial intelligence is being used to select right applicant by the organizations for their talent pool. [6] AI is almost swapping the human intervention in the process of recruitment in some of the software companies. [7]

In a critique published in Forbes Magazine, Walch (2019) suggests that AI is going to create entirely new categories of jobs, whilst killing some of the existing categories. Walch exemplifies that two to three decades back no one even had known a job category called social media marketer. Similarly, in coming two to three decades there will be new categories of employment, which no one can imagine now. [9]

In a study conducted by Accenture and in an article published in MIT Sloan Management Review magazine in Summer 2017 edition, the researchers (Wilson, Daugherty, Morini-Bianzino) identified the emergence of new categories of human jobs, which do not replace the existing ones. In fact, most of the jobs will be new, having no semblance to the jobs of today. The researcher defined these categories as trainers, explainers and sustainers. These categories are representative of AI driven business and technology jobs. [10]

\section{METHODOLOGY}

For this research paper, primary and secondary data is collected. The tools used to collect the data is questionnaire from selected sample and through descriptive qualitative review research articles, periodical, books and journals - both online as well as printed, as well as the experience, learning and observations of the researchers. The field of $\mathrm{AI}$ is growing at break-neck speed, so there are newer things emerging every single day. Review of these emerging information and analysis is part of this methodology.

\subsection{Scope of the Research}

This study will thrust employee in acquiring and accepting the technical advancement. It helps in forming a favourable environment in the working space and social development through enabling processes in the organization. The study can also help in encouraging the employees' optimism and elevated throughput, so that both business and industry would be able to drive maximum gain in terms of human resources management and required skill sets development.

The power of AI is not just going to infest automation traditionally linked to the manufacturing processes. It has rather started making mega strides into the employee's function itself in all domains. AI found its very first takers in the domain of repetitive and predictable processes, which data algorithms could easily replace, bringing higher productivity and efficiency. So the easier targets were routine processes viz. time keeping, payroll processing, resume screening and even the employee induction. The bots, using AI algorithms can very efficiently handle the employee support processes, with human employee not even able to realise that he is interacting with a machine. In today's top organizations, when an employee pushes his or her queries to other department to have an answer by human employee, its highly likely that there is no human on the other side, who is receiving or processing his questions. Same is the case with resume screening and short-listing potential candidates. AI bots are immensely efficient in profiling thousands of resumes in database and mapping them closest to the job description. They can even process the basic transactional interactions and set-up interview schedules. It's said that necessity is mother of invention, when the Human Resources function itself is challenged by AI advancements, it will develop a response mechanism to preserve and reinvent itself. Experience is the biggest teacher, so this reinvention is bound to produce mechanisms for reincarnation of organization processes for future, and managing the human intellect in whole organization itself with changing technological advancement.

\subsection{Objectives of the Research}

- To understand the future employment processes in the age of AI.

- To study the future challenges and development of human talent at workplaces using AI.

\section{SIGNIFICANCE OF THE RESEARCH}

The aim of AI is to create an accurate and error free execution; cost and time saving; increase in productivity and seamlessly perform any job as any human would do i.e. intelligently. The composition of AI is Algorithm, Big Data and Machine Learning. AI, Machine Learning and Automation Technologies; in their current state hold humungous opportunities and realms for the human kind. These fields are not only new but also very vast and intriguing for the future opportunity they hold. Very limited research work has been done in these fields owing to limited funding as well the freshness of the whole technology. It is possible to build upon this study and make a comprehensive research, to make more robust conclusions and recommendations than what author and co-author have submitted at end of this paper. 
Sapna Khatri et al., International Journal of Advanced Trends in Computer Science and Engineering, 9(4), July - August 2020, 5272 - 5277

\section{EXPECTED OUTCOME}

Researcher wishes to establish the correlation between latest in technology and related challenges in employment processes. The opportunities may be different in nature and required different skills to perform it however it is totally depend upon the organizational readiness to adopt it and allow employee to explore it in their domain strategically. The goal of the research is to understand the influence of AI implementation in organization processes and how future job landscape will take the shape. How machine and man can collaborate with each other to get the desirable output in the organization is the key factor of the study. How can employee leverage AI in their tasks to enhance their skills and performance, making it a sign of positive influence?

\section{DISCUSSIONS AND ANALYSIS}

"AI is a tool, not a threat," said by Rodney Brooks. Following example and case study would explain the concept, which will connect the statement made by Rodney Brooks. Bowery farming in New Jersey in the US is a 5 year-old start-up, where the farming is managed by artificially intelligent machines. Every morning when human farmers arrive at the farm, the computer presents to them a list of tasks, which they need to accomplish. The proprietary software uses reams of data collected from farm to derive several important decisions viz. how much to water each plant, the intensity of the light required, when to harvest, etc. The machine is perpetually learning the farming and knows much more than any seasoned farmer would know. This start-up maintains that AI leads to stacked crops and year round growing season making farming 100 times more productive per square meter. Certainly this example shakes all the notions of conventional employment known to human kind.

The unique dimension provided by human senses, is getting replicated scientifically, bringing far more accuracy. This is surely going to disrupt the human dynamics within industry, causing a potential displacement (employment) of humans. Such future employment would mean Human Resource professionals would have to work on creating new chemistry in the organizational culture, where both human intelligence and $\mathrm{AI}$, not only coexist but also compete and collaborate.

Of course, AI also has potential to kill jobs but as Professor Erik Brynjolfsson, MIT Sloan School of Management maintains that any task, which doesn't require human creativity or strengths like interpersonal skills, its potential target of AI based automation. However, Professor also adds that whilst technology may be destroying one kind of jobs, it does end up creating another kind of jobs. Only trick to remain in demand is to remain flexible and ready for newer jobs, some of which are not even known today.

Let us look at one of the very closely known AI application machine to humans - Smart Phones. Today AI supports the augmented reality and virtual reality mobile chipsets, supporting the features viz. facial recognition and transactions using facial recognition. Language translators, Personalized Contextual Automated calls, Camera based benefits, and Voice Assistants, etc. are some of the applications of AI. Whilst one may argue if $\mathrm{AI}$ features of smart phones are making certain kind of jobs redundant, for e.g.: Translators, Photographers, etc. the same AI based applications open a new stream of jobs, that is of programmers, designers, app creators, who can harness the power of AI for human benefits. This very case of smart phones reinforces the contention of Prof Brynjolfsson, who maintains that technology can be enabler for new kind of employment.

At the onset of IT revolution, most feared that computers will take over their lives and jobs. A great sense of insecurity and challenges erupted amongst the public sector employees, government sector employees and even private sector employees, especially those in their late forties or early fifties. They were scared that the kids with computer knowledge will only retain the jobs and it will be a matter of time when oldies will be asked to leave. Many people were also sceptical that new crop of connected organization will usurp the market share from the old. Most underestimated their own capabilities to unlearn and learn. It's just another matter that IT revolution resulted in the opposite. It turned out to be biggest employment sector in India and we ruled the roost of the global IT services scene for decades. Two of the biggest and most prominent IT companies globally by market capitalization (Google \& Microsoft) are led by Indians, and there are many more. With training and support, those naysayers who were scared of losing their jobs, not only learnt to use the computers, they leveraged this new skill sets to improve their productivity as well. A similar situation today exists for the AI. To say the least, best of the educated people are worried that AI will render them redundant.

Organizations and leadership teams are however, alive to the potential of AI and benefits of harnessing this potential for the competitive advantage. Indirectly said, such organizations are tacitly working towards killing some of the routine jobs, fuelling the risk of loss of employment and jobs to AI. However, same organizations are unknowingly fuelling creation of other kind of employment, linked to AI development. So the skill sets needed might be very different from the traditional sectors but the story of IT revolution is likely to be repeated. The business processes are continuously being challenged and adapted to incorporate AI as integral part of these.

The industry is investing not only in the database servers, hardware, software, algorithm but also the human talent to leverage these investments. The key is not about the millions of code lines in algorithm but the talent to create these algorithms and use of it. Like robotic automation, the AI based automation and bots need to taught and trained, to imitate human emotions, feelings, thoughts, cultural perspectives, etc. Such trainings are to be provided by humans, creating a new set of trainer jobs. The training is not of any physical entities but the algorithms, which require a skill set never heard of. Another class of skill sets is of the humans who can explain and decipher the 
decisions of the AI algorithms. And the last class of skill sets for human talent of AI is the evaluators and promoters of AI algorithms.

These are not the only classes of the employment options, which can evolve from AI. There will be scores of other categories that are not known but will get created, as the AI progresses. The existing class of employments and employment processes may also undergo transformation or elimination, as some skill sets / processes will become redundant.

The authors of this paper conducted a pilot research of the impact of AI on employee job structure in Indian industry. The results that emerged were interesting and thought provoking:

1) As seen in Figure 1, 84.7\% respondents clearly agreed that implementation of $\mathrm{AI}$ is promoting horizontal job structure in employee management. This indicates that AI will not just cause the loss of jobs but replacement within the same hierarchal structure. The whole processes of employee management will have a reinvention.

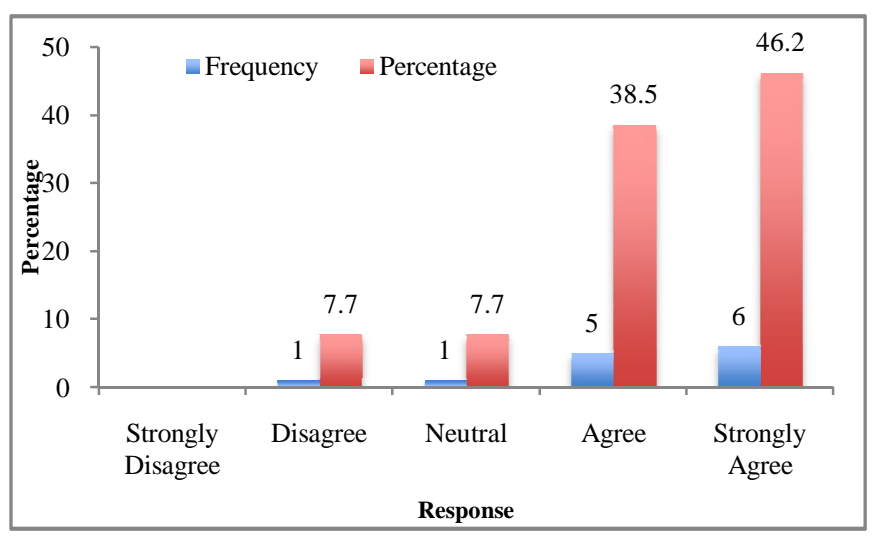

Figure 1: AI - Promoting Horizontal Job Structure

2) As seen in figure 2, 61.6\% respondents remained neutral or disagreed that implementation of $\mathrm{AI}$ is promoting vertical job structure in employee management. This indicates that AI will not create a vertical hierarchy of jobs, indicating elimination of some the levels.

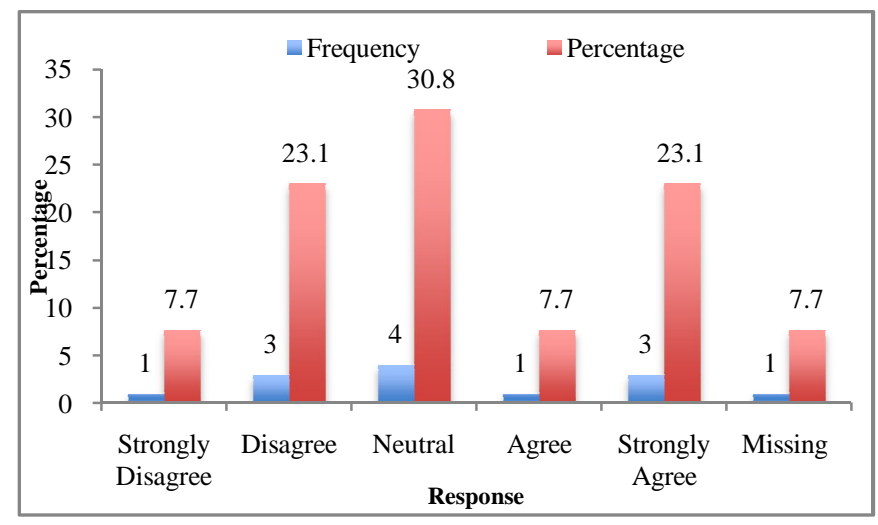

Figure 2: AI - Promoting Vertical Job Structure
The primary research quoted here is a part of a bigger comprehensive research for the doctoral studies, hence cannot be reproduced here in entirety.

\section{CONCLUSION}

The truth is that technology is moving ahead on many skills, which was propriety of human earlier, on the other hand creating demand for new skills. To be future ready, organizations need to prepare themselves through the employment strategies of skill enhancement, new skill development and re-skilling of its human intellect, making these an inseparable part of business processes. Whilst AI may threaten to make humans redundant in certain kinds of jobs, it surely opens new vistas for skill-sets, which would be required to manage the new workplaces, and the future employment structures will have to be created around these. Indeed, there is a potential of totally new job streams, which never existed, and humans would be needed for such jobs to manage the automated workspaces. All the current developments are pointing to the capability of the artificial intelligent systems in excelling in the predictive domain and adversely influence the employment in such domains. But judgement continues to remain the exclusive domain of humans and we face more situations needing judgement, rather than needing prediction. Future employment will be driven towards the judgement jobs \& skill-sets as discussed in the cases cited in discussion.AI Technology is helping employee to take and make decision on the basis of the prediction done by AI. Organizational leadership and the Human Resources have to start steering their energies, focus and strategies in these directions. Future belongs not only to the organizations who adapt and invest in intelligent systems, it will belong to organizations who rewrite their processes, prepare their employees \& employment definitions to productively harness the power of the Big Data and AI for the competitive advantage. Of course future also belongs to young entrepreneurs, who perceive AI as aid to accomplish their goal and willingness to adopt it. The history of human race is a fitting example of Human grit and instincts overcoming all the disruptions, AI will not be an aberration. Future employment processes and strategies will have to recognise this influence of AI and harvest it as key enabler for humans to prevail and remain on the roost.

\section{REFERENCES}

1. Allegis Group, AI and World of Work: Embracing the promises and realities, A White Paper, 2017.Available at, https://www.allegisgroup.com/insights/ai?ecid=ag_ag _gen_ai2017_20170530_bad63f06

2. Bughin, J., Why AI isn't the death of jobs.MIT Sloan Management Review. 2018

3. Gallego, A., Krentz, M., Taplett F. B., Tsusaka, M. and Yousif, N., How AI Could Help-or HinderWomen in the Workforce. Boston Consulting Group, 2019.

4. Goos, M. and Manning, A., Lousy and lovely jobs: The rising polarization of work in Britain. The 
review of economics and statistics, 89(1), pp.118-133. 2007

https://doi.org/10.1162/rest.89.1.118

5. Khatri S., Pandey D.K., Penkar D., Ramani J.Impact of AI on Human Resources. Data Management, Analytics and Innovation. Advances in Intelligent Systems and Computing, vol 1016. Springer, Singapore, 2020.

6. Nawaz, N., Artificial Intelligence Is Transforming Recruitment Effectiveness in CMMI Level Companies. International Journal of Advanced Trends in Computer Science and Engineering, 8(6), November - December 2019, Available at SSRN: https://ssrn.com/abstract=3521928

https://doi.org/10.2139/ssrn.3521928

7. Nawaz, N., Artificial Intelligence Interchange Human Intervention in the Recruitment Process in Indian Software Industry. Volume 8, No.4, July August 2019 International Journal of Advanced Trends in Computer Science and Engineering, Available at SSRN: https://ssrn.com/abstract=3521912 or http://dx. doi.org/10.2139/ssrn.3521912

8. Petropoulos, G. The impact of AI on employment. Praise for Work in the Digital Age, 119, 2018.

9. Walch, K. Is AI a Job Killer or Job Creator? Cognitive World, Forbes Media, Fobes.com, 2019.

10. Wilson H.J., Daugherty P.R., Morini-Bainzino N. The Jobs that AI will create. MIT Sloan Management Review, 2017.

11. Charniak E., McDermott D.,Introduction into Artificial Intelligence, Addison-Wesley, 1995

12. Cummings \& Worley, Organization Development and Change, Published by CENGAGE Learning, 2010

13. Dessler Garry, Human Resources Management, Published by Prentice Hall, 2015.

14. Durai Pravin,Human Resources Management, Pearson Publication, 2010

15. https://sloanreview.mit.edu

16. https://www.bcg.com

17. https://www.mckinsey.com

18. https://www.iotforall.com 